\title{
Optical coherence tomography patterns of diabetic macular edema in a Saudi population
}

This article was published in the following Dove Press journal:

Clinical Ophthalmology

\author{
Sanaa A Yassin (D) \\ Saud M ALjohani' \\ Arwa Z Alromaih ${ }^{2}$ \\ Abdulaziz A Alrushood' \\ 'Department of Ophthalmology, Imam \\ Abdulrahman Bin Faisal University, \\ Dammam, Saudi Arabia; ${ }^{2}$ College of \\ Medicine, Imam Abdulrahman Bin Faisal \\ University, Dammam, Saudi Arabia
}

Purpose: The study aims to describe the patterns of diabetic macular edema (DME) and their association with visual acuity using optical coherence tomography (OCT).

Patients and methods: This is a retrospective observational study with chart review of patients with DME including both type 1 and 2 diabetics seen between January 2015 and January 2016.

Main Outcome Measures: Type of diabetes, diabetes duration, best-corrected visual acuity, DME pattern, central macular thickness (CMT), and stage of diabetic retinopathy. DME was classified based on OCT scans into: sponge-like diffuse retinal thickness (SLDRT), cystoids macular edema (CME), and sub-retinal fluid (SRF).

Results: 227 eyes (144 patients) were included. The SLDRT represented 67.84\%, CME 19.82\%, and presence of SRF $2.20 \%$. OCT scan from 21 patients (22 eyes) displayed more than a single pattern. The CMT and visual acuities varied depending on the DME morphologic patterns. SLDRT was associated with the least affected mean visual acuity of $0.2 \pm 0.21$. SRF signified the worst mean visual acuities. Increase in CMT significantly correlated with reduced visual acuity $(P=0.005)$. A statistically significant positive correlations between diabetic stage- high risk proliferative diabetic retinopathy (PDR) and severe non-proliferative diabetic retinopathy (NPDR) - with the $\operatorname{CMT}(P=0.050)$ and $(P=0.021)$ respectively, were observed. A significant positive correlation between the duration of diabetes, age and type 1 diabetes with visual acuity in $\operatorname{LogMAR}(\mathrm{P}=0.003)$, $(P=0.03)$, and $(P=0.0005)$ respectively.

Conclusions: SLDRT was the most common morphological subtype of DME patterns and increasing retinal thickness impaired the visual acuity. Older ages, longer diabetic duration and type 1 diabetes are considered significant risk factors for visual acuity impairment. The study also suggests that there is a significant correlation between the DME patterns and visual acuity.

Keywords: diabetic retinopathy, optical coherence tomography pattern, diabetic macular edema, DME morphologic patterns

\section{Introduction}

Diabetes is a chronic and debilitating condition that affects $8.5 \%$ of adults aged 18 years and older worldwide and one of the leading global causes of morbidity and mortality rates. ${ }^{1}$ According to the Saudi Arabian Ministry of Health, in 1992 there were 0.9 million people diagnosed with diabetes, and in 2010 this figure increased to 2.5 million people. ${ }^{2}$ Thus, with high global prevalence rates of diabetes, associated complications such as: diabetic macular edema (DME) among diabetic patients is a serious health concern. DME carries deleterious sight-threatening risk. Studies have shown a significant correlation between retinal thickness and
Correspondence: Sanaa A Yassin Department of Ophthalmology, Imam Abdulrahman Bin Faisal University, Dammam, PO Box 40097, Al-Khobar 31952, Saudi Arabia

Tel +966138950213

Fax +966138966776

Email syassin@iau.edu.sa 
visual acuity. ${ }^{3,4}$ DME is believed to affect up to $15 \%$ of diabetic patients almost two decades since diagnosis. ${ }^{3}$ Several studies have demonstrated that about a quarter of diabetic patients may develop certain types of diabetic retinopathy, with incidence rates increasing significantly by the diabetic duration. ${ }^{5-7}$

DME develops when fluid leaks from incompetent vascular bed and accumulates in the retina. ${ }^{8}$ Diabetic retinopathy progresses through a series of stages: mild, moderate, severe non-proliferative diabetic retinopathy (NPDR), proliferative diabetic retinopathy (PDR), to highrisk PDR. The earlier diagnostic assessment methods of DME, including indirect funduscopic examination, stereoscopic photography, slit-lamp biomicroscopy, and fluorescence angiography have failed to provide an efficient and reliable quantification of the macular edema. ${ }^{4,7-17}$ In addition, studies have affirmed that the previously adopted methods have a limited capacity to assess retinal thickness, and insufficient sensitivity to determine the unique details of the area examined. ${ }^{5,17}$ Monitoring of DME has significantly improved with the new advances and the development of objective techniques for the quantitative measurements of macular edema, ${ }^{5,18-21}$ including techniques like Heidelberg retinal tomography, retinal thickness analyzer and optical coherence tomography (OCT). ${ }^{14,22}$

The introduction of OCT in DME evaluation has unquestionably provided accurate and better measurements, ${ }^{10,23}$ with a sensitive and noninvasive technique ${ }^{16}$ that produced highresolution images capable of determining subtle macular thickness in vivo measurements. ${ }^{15}$ OCT has widely been applied in measurements of central macular thickness (CMT) in healthy eyes. ${ }^{11,14,23}$ In addition, OCT proved vital in the diagnosis, and monitoring the response and/or the progression of diabetic retinopathy. ${ }^{24}$ The role of OCT has substantially been investigated for classification of the morphological pattern of DME. ${ }^{3,4,7,8,10,13,17,25,26}$ Consequently, it facilitated the identification and description of several OCT-based DME patterns including; sponge-like diffuse retinal thickness (SLDRT), cystoid macular edema (CME), and the presence of subretinal fluid (SRF). Several studies have shown SLDRT to be the most common pattern while the SRF pattern has been associated with the worst visual acuity. ${ }^{3,4,12,15,27}$ Recently, an innovative technique in OCT was introduced for imaging of the retinal microvasculatures known as OCT angiography (OCT-A). OCT-A is noninvasive procedure that is able to identify foveal capillary nonperfusion early in the course of the disease. ${ }^{28}$ Even OCT-A has an advantage over fundus fluorescein angiography of visualizing the different layers of foveal avascular zone (FAZ) individually. ${ }^{29,30} \mathrm{FAZ}$ area and vascular density were used as measures of diabetic macular ischemia and were found to correlate with visual acuity in patients with diabetic retinopathy (DR) even without DME. ${ }^{31}$ The evolving OCT-A proficiency is increasingly employed in clinical practice.

The lack of data in Saudi Arabia, concerning the prevalence of the currently known OCT patterns of DME, prompted this study to evaluate the DME pattern prevalence with the OCT scan, and further correlate the patterns to DME with the visual acuity, duration of diabetes and stage of diabetic retinopathy among the Saudi population.

\section{Patients and methods}

In this study, a retrospective chart review was performed on all diabetic patients (both type 1 and 2) with DME who undertook OCT evaluation at Al-Kahhal Medical Complex, Dammam, Saudi Arabia within a year from the period of January 2015 and January 2016. The study was approved by the Dhahran Eye Specialist Hospital-Institutional Review Board (DESHIRB) and adhered to the tenets of the Declaration of Helsinki. Informed verbal consent was obtained from the all subjects in this study as approved by DESH-IRB. The inclusion criteria included diabetic patients with evidence of DME on clinical biomicroscopic, funduscopic examinations, who had an OCT evaluation with CMT more than $250 \mu \mathrm{m}$ within $500 \mu \mathrm{m}$ from the center of the fovea and/or more than $300-\mu \mathrm{m}$ macular thickness within $1,500 \mu \mathrm{m}$ from the center of the fovea. Furthermore, a comprehensive review of all patient records and collection of data included gender, type of diabetes, diabetes duration, refraction, best-corrected Snellen visual acuity, and stage of diabetic retinopathy was made. Snellen visual acuities were converted to the LogMAR scale. The sampled number met the threshold number required in medical research to give a reproducible result as defined by Schimel et al. ${ }^{12}$ The exclusion criteria included; any diabetic patient, who received intravitreal injections, and/or who had tractional retinal detachment or vitreomacular traction. In addition, eyes with poor quality OCT scan or any other process that prohibited proper grading of OCT scan were excluded. In addition, patients having eyes with glaucoma, uveitis, retinitis pigmentosa and choroidal neovascular membrane were also excluded.

For each patient, the CMT was measured using a highdefinition spectral domain-optical coherence tomography (SD-OCT) (Cirrus HD-OCT; Carl Zeiss, Oberkochen, Germany). The OCT scans were performed by an experienced operator. Prior to the examination, the pupils were 
dilated. To measure the thicknesses of the macula the examiner obtained retinal images by performing $512 \times 128$ scan pattern where a $6 \times 6-\mathrm{mm}$ area on the retina is scanned with 128 horizontal lines, each consisting of 512 A-scans per line (total of 65,536 sampled points) within a scan time of 2.4 seconds. CMT in all four quadrants: superior, nasal, inferior and temporal, as well as mean were recorded. Internal fixation was used to ensure proper alignment of the eye. If the patient had poor fixation, the image could be centered on the macula by the photographer according to the fundus image generated by the machine. Only scans with signal strength of at least six were accepted.

The appearance of images on the OCT monitor of the 144 patients was the sole criteria for scoring the patterns. The criteria of scoring were based on the size of the retinal thickness greater than $250 \mu \mathrm{m}$ characterized by smaller interretinal reflectivity and broad layers of reflectivity higher than $250 \mu \mathrm{m}$ was defined as SLDRT, presence of CME was shown by the presence of oval and round parts of the image indicating low reflect-ability. SRF was identified by dome-like fluid accumulation in the subretinal space (Figure 1). The central macular thicknesses in diabetic patients were compared with values of normal retinal thicknesses in Saudi as established by Al-Zamil, which had a mean of $244.76 \pm 23.62 \mu \mathrm{m}^{23}$
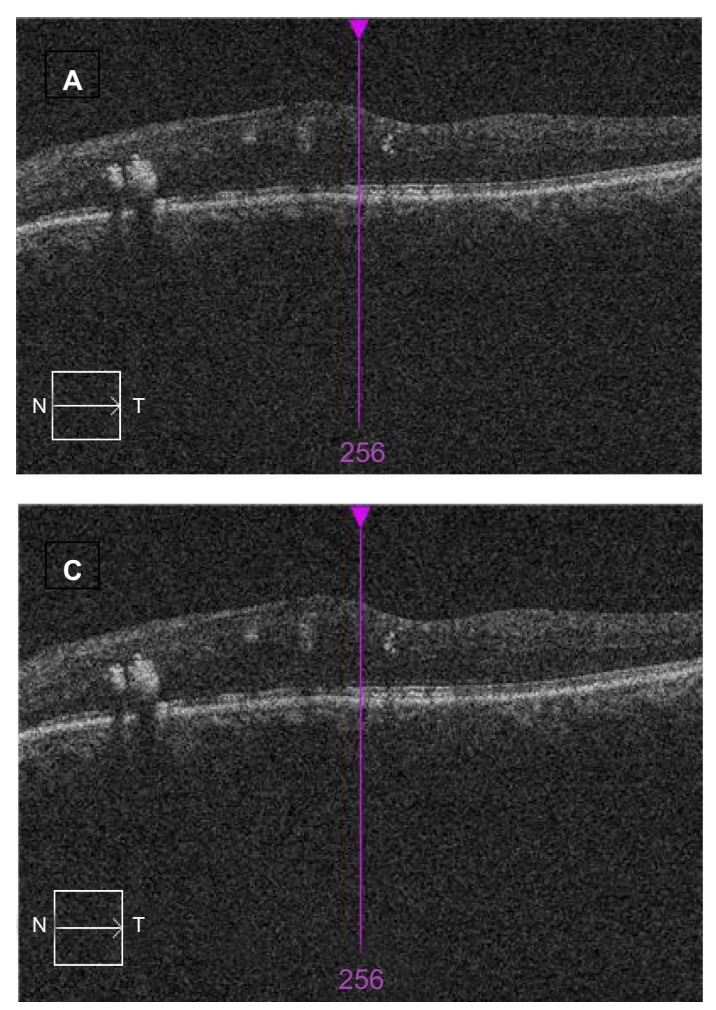

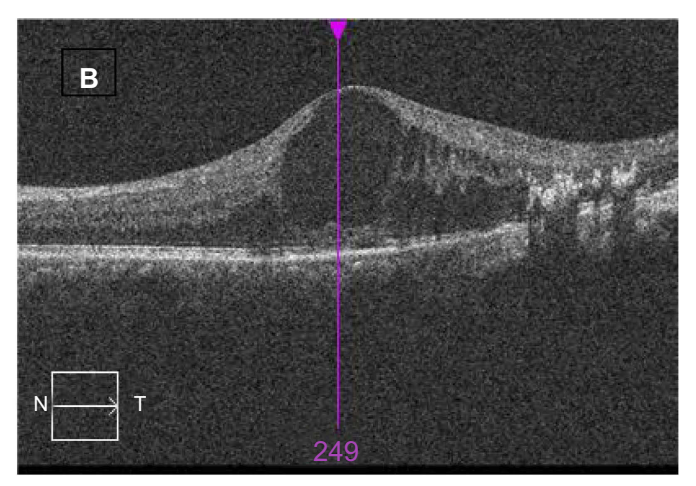

The data was analyzed using IBM SPSS Statistics Grad Pack 25.0 Standard (IBM Corporation, Armonk, NY, USA), for the determination of significant associations Pearson correlation and multiregression analysis were performed. The study investigated the existence of correlations between various morphologic subtypes of DME pattern, CMT, stage of diabetic retinopathy, and visual acuity. A $P$-value less than 0.05 was considered statistically significant.

\section{Results}

The study included 144 diabetic patients (227 eyes), 69 females and 75 males, with mean age 57.86 \pm 37.86 years (ranging from 20-85). The studied cohort included 56 type 1 , and 88 type 2 diabetic patients. The average duration of diabetes was $17.4 \pm 8.2$ years. Among the 144 diabetic patients, 11 were diagnosed as early PDR stage, 29 were high-risk PDR, and 21 were mild NPDR, 69 moderate NPDR, while 14 were severe NPDR stages.

OCT scan displayed three main patterns, namely; SLDRT (67.84\% representing 154 eyes), CME (19.82\% representing 45 eyes), and SRF (about 2.20\% representing 5 eyes) (Table 1). OCT scan from 23 eyes of 21 patients displayed more than a single pattern (Table 1).

Figure I Morphological calcification of optical coherence tomography (OCT) patterns in diabetic macular edema demonstrating (A) sponge-like diffuse retinal thickness (SLDRT), (B) cystoid macular edema (CME), and (C) subretinal fluid (SRF). 
Table I Summary of the frequency of OCT based DME morphological patterns

\begin{tabular}{|l|l|l|}
\hline Pattern present & $\begin{array}{l}\text { Number } \\
\text { of eyes }\end{array}$ & $\begin{array}{l}\text { Percentage } \\
\%\end{array}$ \\
\hline Sponge-like retinal diffuse-thickness & 154 & 67.84 \\
Cystoid macular edema & 45 & 19.82 \\
Subretinal fluid & 5 & 2.20 \\
Cystoid/spongy & 11 & 4.85 \\
Cystoid/subretinal fluid & 9 & 3.96 \\
Spongy/subretinal fluid & 2 & 0.88 \\
Spongy/cystoid/subretinal fluid & 1 & 0.44 \\
\hline
\end{tabular}

Abbreviations: OCT, optical coherence tomography; DME, diabetic meacular edema.

Table 2 Mean visual acuity and retinal thickness within subtypes of DME

\begin{tabular}{|l|l|l|l|}
\hline $\begin{array}{l}\text { Morphologic } \\
\text { subtype }\end{array}$ & $\begin{array}{l}\text { LogMAR visual } \\
\text { acuity (mean } \pm S D)\end{array}$ & $\begin{array}{l}\text { CMT } \\
(\mu \mathrm{m}) \\
(\mathbf{m e a n} \\
\mathbf{\pm S D})\end{array}$ & $\begin{array}{l}\text { Range } \\
(\boldsymbol{\mu m})\end{array}$ \\
\hline SLDRT & $0.20 \pm 0.21$ & $287 \pm 201$ & $185-488$ \\
CME & $0.41 \pm 0.01$ & $382 \pm 250$ & $216-632$ \\
SRF & $0.62 \pm 0.21$ & $382 \pm 166$ & $290-548$ \\
\hline
\end{tabular}

Abbreviations: DME, diabetic macular edema; CMT, central macular thickness; SLDRT, sponge-like diffuse retinal thickness; CME, cystoids macular edema; SRF, subretinal fluid.

The macular thickness varied according to the pattern of DME, the mean CMT in SLDRT was $287 \pm 201 \mu \mathrm{m}$, in CME was $382 \pm 250 \mu \mathrm{m}$, and in SRF was $382 \pm 166 \mu \mathrm{m}$ (Table 2).

The overall mean visual acuity in LogMAR was 0.41 \pm 0.33 . The worst mean visual acuity of the DME morphologic patterns was seen in eyes with SRF $(0.62 \pm 0.21), P=0.004$ (Table 2 and Table 3). There was a statistically significant correlation between morphologic patterns (SLDRT, CME, and SRF) and visual acuity with $P$-values $(0.008,0.005$, and 0.004) respectively.

Table 3 Correlations between morphologic subtypes with visual acuity

\begin{tabular}{|l|l|l|l|}
\hline $\begin{array}{l}\text { Morphologic } \\
\text { subtype }\end{array}$ & $\begin{array}{l}\text { Coefficients } \\
(\boldsymbol{r})\end{array}$ & $\begin{array}{l}\text { (P-values) } \\
\text { LogMAR } \\
\text { visual } \\
\text { acuity } \\
\text { (mean } \\
\mathbf{\pm S D})\end{array}$ \\
\hline SLDRT & 0.653 & $0.008^{*}$ & $0.20 \pm 0.21$ \\
CME & 0.473 & $0.005^{*}$ & $0.41 \pm 0.01$ \\
SRF & 0.520 & $0.004^{*}$ & $0.62 \pm 0.21$ \\
\hline
\end{tabular}

Note: $* P<0.05$.

Abbreviations: SLDRT, sponge-like diffuse retinal thickness; CME, cystoids macular edema; SRF, sub retinal fluid.
There was a positive correlation between diabetic stage and macular thickness; with high-risk PDR $P=0.050$ and severe NPDR $P=0.021$ being statistically significant (Table 4). Besides, there was also a positive correlation between diabetic stage (severe NPDR and high-risk PDR) with morphological patterns (SLDRT and CME) (Table 5).

There was a positive correlation between CMT and visual acuity measurement with mean visual acuity in LogMAR $0.41 \pm 0.33, r=0.473$ and $P=0.005$, and a positive linear regression (Figure 2).

The correlation of DME patterns with age, and duration of diabetes were also examined. Out of 144 patients, 83 patients $(57.6 \%)$ were experiencing DME bilaterally while 35 (24.3\%) and 26 (18.1\%) patients were experiencing DME on their right eye and left eye respectively. In addition, results showed a positive correlation between diabetic duration, age and type 1 diabetes with visual acuity in LogMAR measurements with $(r=0.027$, $P=0.003),(r=0.218, P=0.030)$ and $(r=0.342, P=0.0005)$ respectively as shown in (Figure 3, Figure 4 and Table 6).

\section{Discussion}

The identification of the DME pattern is essential in predicting the evolution of the disease and its response to treatment; with the sponge-like type being designated to have a better outcome than the other two subtypes. ${ }^{4,32}$ In the current study, the most commonly observed DME subtype was SLDRT. However, the frequency of SLDRT was less than that described earlier, being present in $67.84 \%$ of the DME. CME was the second-most frequent with a frequency of $19.82 \%$, while the SRF was present in $2.20 \%$ of 5 eyes. In comparison with the frequency that was reported by others sponge-like type varied between $45-97 \%{ }^{3-5,25,32,33}$

This study also confirmed that the occurrence of a specific OCT pattern does not exclude other patterns from occurring within the same eye. . $^{5,17,24,34,35}$ However, only a limited number of cases $9.69 \%$ (23 eyes) of 21 patients had more than one pattern observed (Table 1). Consequently, this showed that spongy/ cystoid DME is the most common while spongy/ cystoid/SRF is the least common. In contrast to our findings, Kim et al's ${ }^{4}$ study reported combination of different patterns of DME occurring in $44.3 \%$ of eyes. However, the most common combination was spongy/ cystoid DME described in $29 \%$ of eyes. ${ }^{4}$

In agreement with literature, ${ }^{7,36-38}$ this study also found that visual acuity varied with different DME 
Table 4 Correlations between diabetic stage and macular thickness

\begin{tabular}{|l|l|l|l|l|l|}
\hline Diabetic stage & Number of eyes & $\begin{array}{l}\text { CMT }(\boldsymbol{\mu m}) \\
(\mathbf{m e a n} \mathbf{+ S D})\end{array}$ & LogMAR visual acuity (mean \pm SD) & Coefficients $(\boldsymbol{r})$ & $P$-values \\
\hline Mild NPDR & 37 & $305 \pm 59$ & $0.19 \pm 0.14$ & 0.217 & 0.419 \\
Moderate NPDR & 112 & $318 \pm 80$ & $0.44 \pm 0.26$ & 0.362 & 0.312 \\
Severe NPDR & 23 & $374 \pm 136$ & $0.37 \pm 0.38$ & 0.214 & 0.301 \\
Early PDR & 19 & $319 \pm 113$ & $0.26 \pm 0.40$ & 0.408 & $0.021 *$ \\
High risk PDR & 36 & $351 \pm 109$ & $0.40 \pm 0.31$ & $0.050^{*}$ \\
\hline
\end{tabular}

Note: $* P<0.05$.

Abbreviations: CMT, central macular thickness; NPDR, nonproliferative diabetic retinopathy; PDR, proliferative diabetic Retinopathy.

Table 5 Correlations between diabetic retinopathy stage and subtypes of DME

\begin{tabular}{|l|l|l|l|}
\hline $\begin{array}{l}\text { Diabetic } \\
\text { stage }\end{array}$ & $\begin{array}{l}\text { SLDRT } \\
\boldsymbol{P} \text {-values }\end{array}$ & $\begin{array}{l}\text { CME } \\
\boldsymbol{P} \text {-values }\end{array}$ & $\begin{array}{l}\text { SRF } \\
\boldsymbol{P} \text {-values }\end{array}$ \\
\hline Mild NPDR & 0.126 & 0.209 & 0.619 \\
Moderate NPDR & 0.215 & 0.176 & 0.204 \\
Severe NPDR & $0.013^{*}$ & 0.108 & 0.236 \\
Early PDR & 0.107 & 0.481 & 0.467 \\
High risk PDR & $0.024^{*}$ & $0.034^{*}$ & 0.127 \\
\hline
\end{tabular}

Note: $* P<0.05$.

Abbreviations: DME, diabetic macular edema; SLDRT, sponge-like diffuse retinal thickness; CME, cystoids macular edema; SRF, subretinal fluid; NPDR, nonproliferative diabetic retinopathy; PDR, proliferative diabetic retinopathy.

patterns (Table 3). All DME OCT patterns; SLDRT, CME and SRF showed significant positive correlations with visual acuity in LogMAR with $P$-values of $0.008,0.005$, and 0.004 respectively (Table 3 ). However, as per this study's findings, visual acuity was better among the patients with the spongy pattern compared with the other patterns. This difference in level of visual acuity with different patterns can be explained based on the corresponding mean retinal thickness associated with the DME pattern, and which is believed to be directly affecting vision. $6,39,40$

The study established a statistically significant positive correlation between diabetic retinopathy stage (high-risk PDR and severe NPDR) and the CMT $(P=0.050)$ and $(P=0.021)$ respectively (Table 4$)$. This finding is in agreement with Browning et $\mathrm{al}^{41}$ who found that severe NPDR and PDR eyes had thicker macula in comparison to other stages.

Similarly, the study established a significant positive correlation between the severe NPDR stage of diabetic retinopathy with morphological pattern SLDRT with $P=0.013$ and high-risk PDR with SLDRT and CME with $P=0.024$ and $P=0.034$ respectively (Table 5 ). In contrast to Alkuraya et $\mathrm{al}^{5}$ the prevalence of SLDRT was significantly higher in eyes with mild-to-moderate NPDR than in eyes with severe NPDR to proliferative retinopathy $P=0.0069$. Moreover, the prevalence of SRF was significantly higher in eyes with severe NPDR to PDR than in eyes with mildto-moderate NPDR $P=0.0056$. However, there was an agreement between the two studies regarding SLDRT that had significantly the best visual acuity and the SRF that had the worst visual acuity, and that CMT was significantly thicker in SRF eyes than in eyes with SLDRT.

The current study was in line with most of the previous studies regarding the effects of increased CMT on visual acuity and supporting that the thicker the retinal layer, the greater the visual impairment (Table 2). ${ }^{3-6,10,33}$ Moreover, there was a significant positive correlation between CMT and visual acuity in LogMAR, $P=0.005$, (Table 3 ). The correlation of the duration of diabetes, age of diabetic patients, type of diabetes, and gender to visual acuity were also examined. There was a positive correlation between the duration of diabetes, age and type 1 diabetes with visual acuity in $\operatorname{LogMAR}(P=0.003),(P=0.03)$, and $(P=0.0005)$ respectively (Table 6$)$. Thus, the duration of diabetes, age, and type 1 diabetes were recognized to be possible contributing risk factors for consideration, being statistically significant. Similarly Ghosh et $\mathrm{al}^{8}$ found the duration of diabetes has a significant correlation with CMT $P=0.002, r=0.440$. Likewise, older age and type 1 diabetes were found to be significant risk factors for DME as in the studies by Asensio et $\mathrm{al}^{42}$ and Acan et al, ${ }^{15}$ respectively.

Limitations of the study include its retrospective design, and the difficulty to rule out ischemic changes as a contributing factor for visual acuity loss due to unavailability of OCT-A at time of conducting the study. OCT-A can measure the FAZ area and vascular density in diabetic macular ischemia and was found to correlate with visual acuity in patients with DR even without DME. ${ }^{31}$

Our study showed that SLDRT pattern offered the best visual acuity, and was the most common OCT scan pattern 


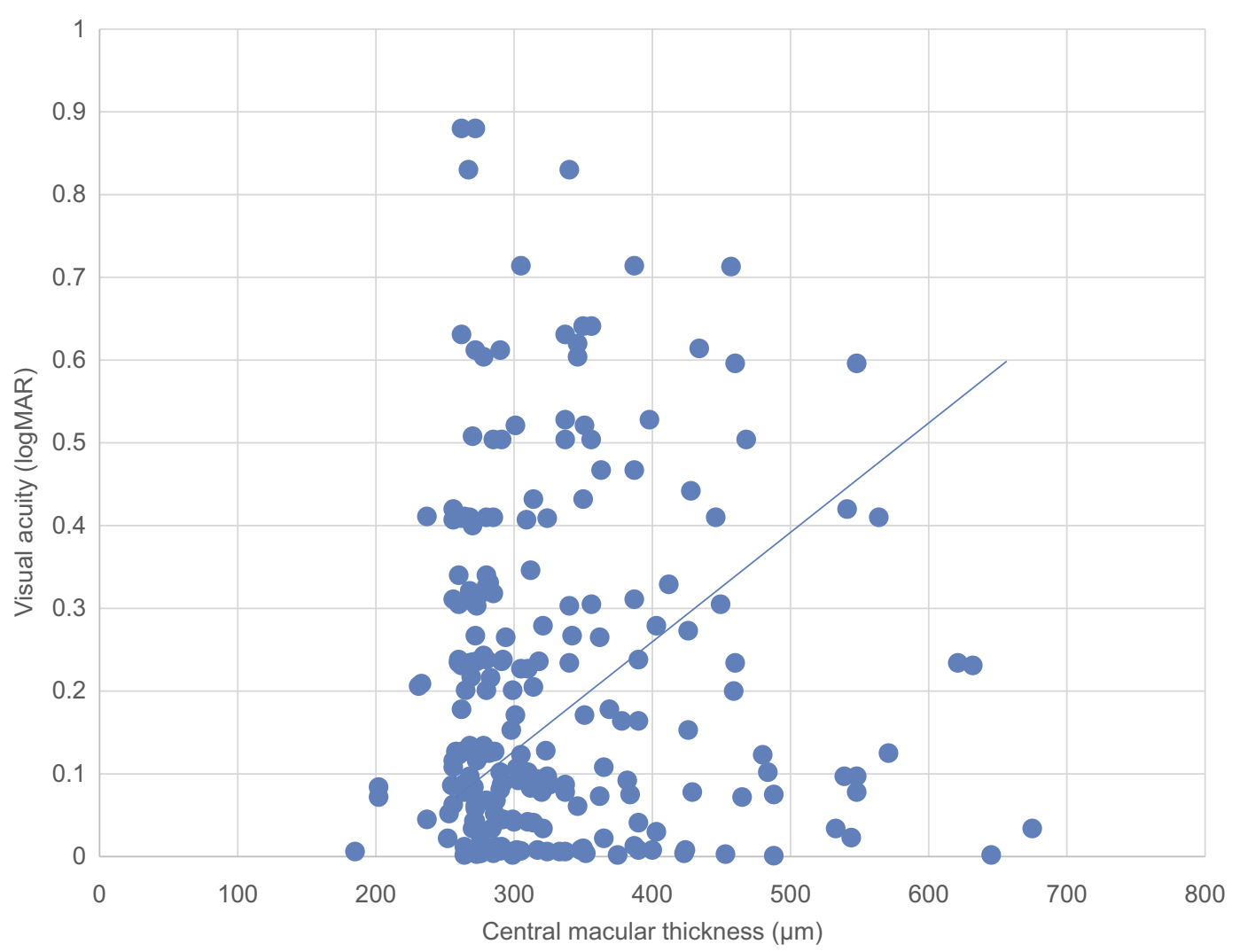

Figure 2 Graph showing relationship between central macular thickness (CMT) and visual acuity.

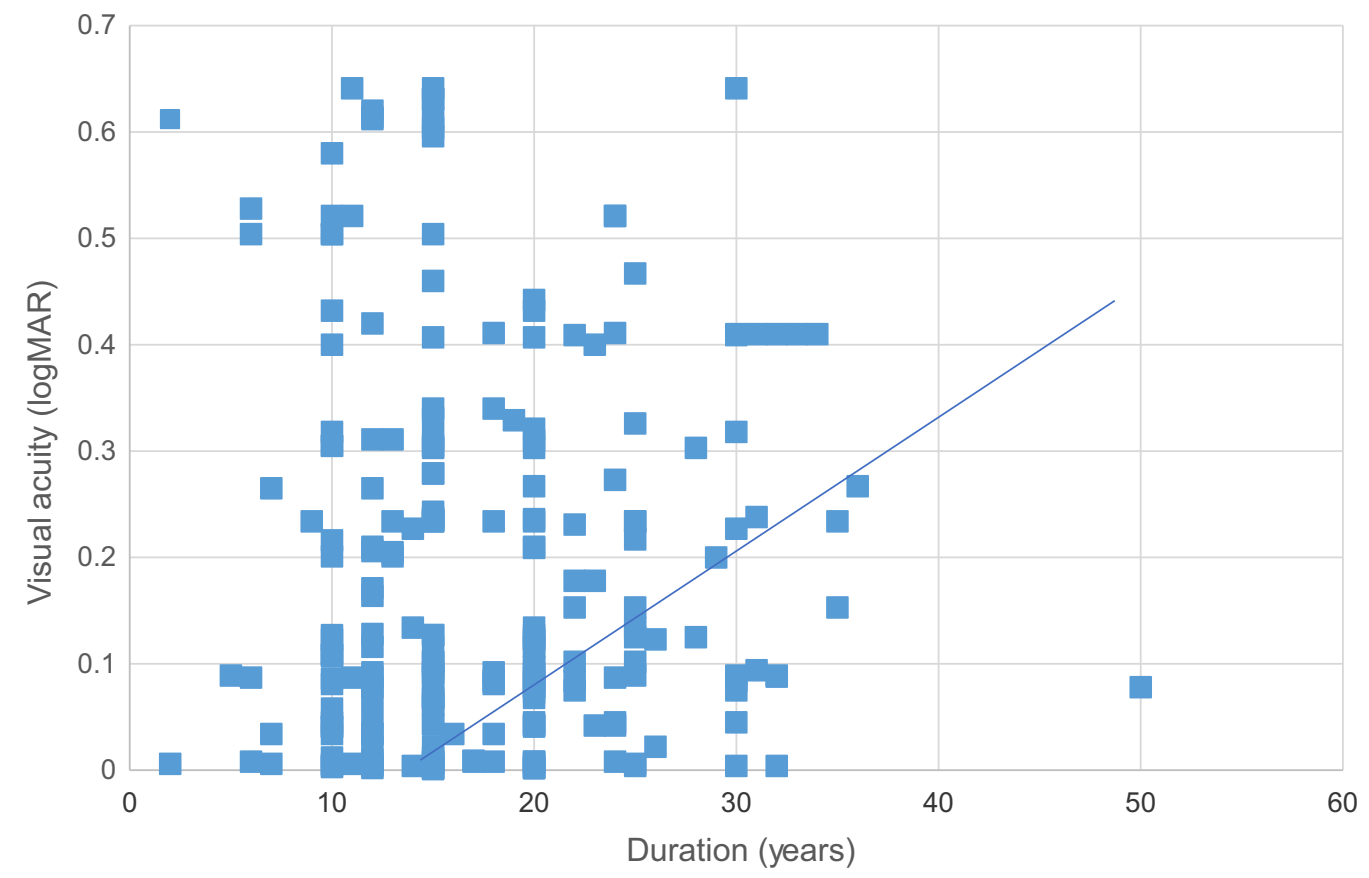

Figure 3 Graph showing relationship between duration and visual acuity (LogMAR).

amongst the DME patients in the Saudi population; and that increased retinal thickness correlated with reduced visual acuity and diabetic retinopathy stage. Additionally, older age, duration of diabetes, type 1 diabetes and diabetic retinopathy stage are considered significant risk factors for visual acuity impairment in patients with DME. 


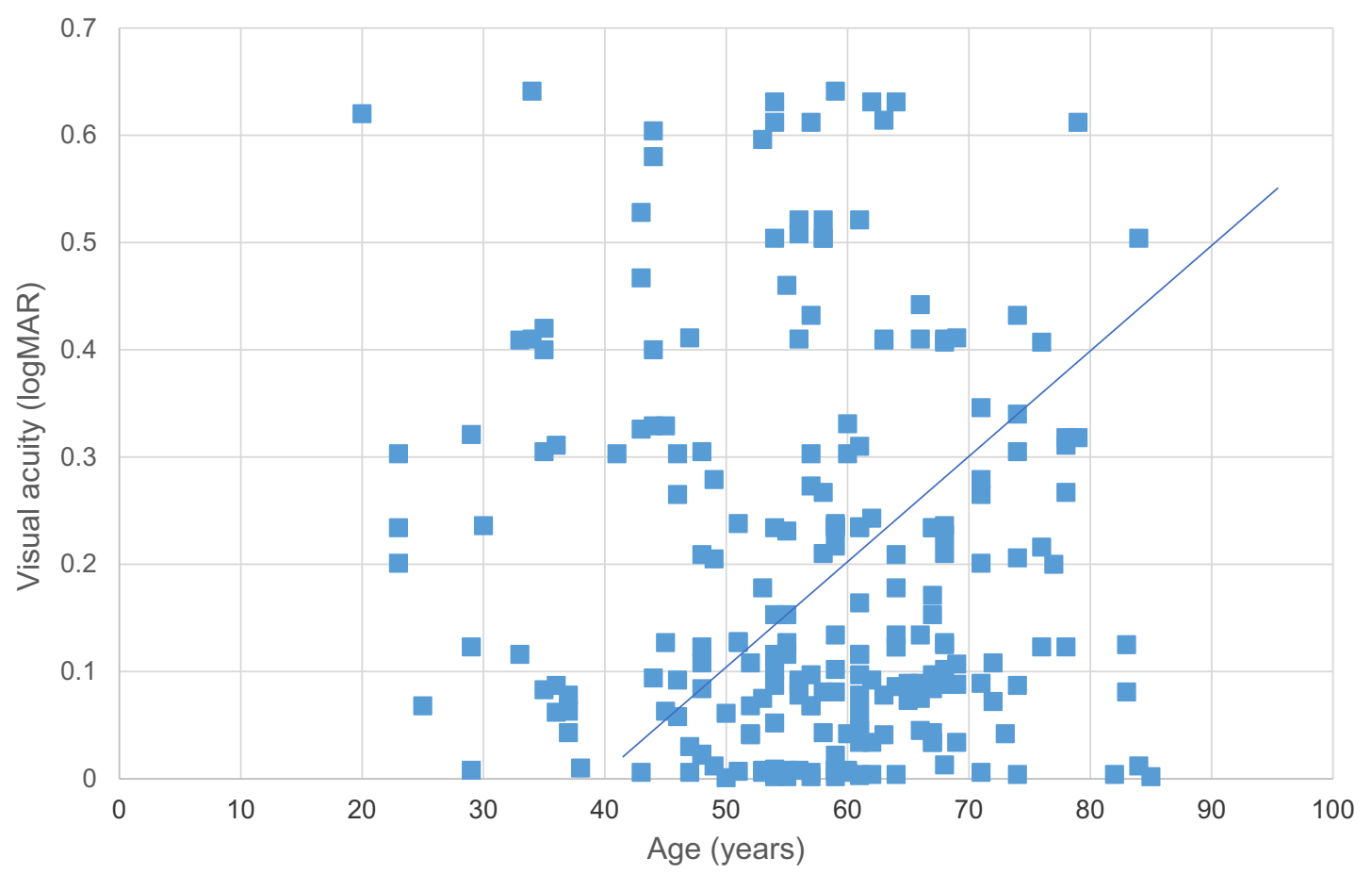

Figure 4 Graph showing relationship between age and visual acuity (LogMAR).

Table 6 Significant correlations of diabetic type, age, and duration with visual acuity

\begin{tabular}{|c|c|c|c|}
\hline $\begin{array}{l}\text { Type of } \\
\text { variable }\end{array}$ & $\begin{array}{l}\text { Coefficients } \\
\text { (r) }\end{array}$ & (P-values) & $\begin{array}{l}\text { LogMAR } \\
\text { visual } \\
\text { acuity } \\
\text { (mean } \\
\text { 土SD) }\end{array}$ \\
\hline Diabetes type I & 0.255 & $0.0005^{*}$ & $0.34 \pm 0.33$ \\
\hline Diabetes type 2 & 0.330 & 0.162 & $0.26 \pm 0.25$ \\
\hline Diabetic duration & 0.027 & $0.003 *$ & $0.29 \pm 0.29$ \\
\hline Age (years) & 0.218 & $0.030 *$ & $0.29 \pm 0.29$ \\
\hline
\end{tabular}

Note: Correlation between visual acuity and type I Diabetes $P=0.0005 \quad(P<0.00$ I) was statistically significant. $* P<0.05$

\section{Disclosure}

The authors report no conflicts of interest in this work.

\section{References}

1. WHO. Diabetes/Fact sheets; 2017. Available from http://www.who.int/ news-room/fact-sheets/detail/diabetes. Accessed october 30, 2018.

2. Alotaibi A, Perry L, Gholizadeh L, Al-Ganmi A. Incidence and prevalence rates of diabetes mellitus in Saudi Arabia: an overview. $J$ Epidemiol Glob Health. 2017;7(4):211-218. doi:10.1016/j. jegh.2017.10.001

3. Ahmadpour-Baghdadabad M, Manaviat M, Shojaoddiny-Ardekani A. Optical coherence tomography in diabetic macular edema: patterns and related risk factors. NEPJOPH. 2013;5(2):190-194. doi:10.3126/nepjoph.v5i2.8727
4. Kim BY, Smith SD, Kaiser PK. Optical coherence tomographic patterns of diabetic macular edema. Am J Ophthalmol. 2006;142 (3):405-412. doi:10.1016/j.ajo.2006.04.023

5. Alkuraya H, Kangave D, Abu El-Asrar AM. The correlation between optical coherence tomographic features and severity of retinopathy, macular thickness and visual acuity in diabetic macular edema. Int Ophthalmol. 2005;26(3):93-99. doi:10.1007/s10792-006-9007-8

6. Otani T, Yamaguchi Y, Kishi S. Correlation between visual acuity and foveal microstructural changes in diabetic macular edema. Retina. 2010;30(5):774-780. doi:10.1097/IAE.0b013e3181c2e0d6

7. Talu SD. Optical coherence tomography in the diagnosis and monitoring of retinal diseases. Int Sch Res Not Biomed Imaging. 2013;2013(2013):1-13.

8. Ghosh S, Bansal P, Shejao H, Hegde R, Roy D, Biswas S. Correlation of morphological pattern of optical coherence tomography in diabetic macular edema with systemic risk factors in middle aged males. Int Ophthalmol. 2015;35(1):3-10. doi:10.1007/s10792-014-9922-z

9. Byeon SH, Chu YK, Hong YT, Kim M, Kang HM, Kwon OW. New insights into the pathoanatomy of diabetic macular edema: angiographic patterns and optical coherence tomography. Retina. 2012;32 (6):1087-1099. doi:10.1097/IAE.0b013e3182349686

10. Browning DJ, Glassman AR, Aiello LP, et al. Relationship between optical coherence tomography-measured central retinal thickness and visual acuity in diabetic macular edema. Ophthalmology. 2007;114 (3):525-536. doi:10.1016/j.ophtha.2006.06.052

11. Gella L, Raman R, Sharma T. Macular thickness measurements using Copernicus spectral domain optical coherence tomography. Saudi J Ophthalmol. 2015;29(2):121-125. doi:10.1016/j.sjopt.2014.10.003

12. Schimel AM, Fisher YL, Flynn HW Jr. Optical coherence tomography in the diagnosis and management of diabetic macular edema: time-domain versus spectral-domain. Ophthalmic Surg Lasers Imaging. 2011;42 (Suppl):S41-S55. doi:10.3928/15428877-20110627-04

13. Ishibazawa A, Nagaoka T, Takahashi A, et al. Optical coherence tomography angiography in diabetic retinopathy: a prospective pilot study. $\mathrm{Am}$ J Ophthalmol. 2015;160(1):35-44.e31. doi:10.1016/j.ajo.2015.04.021 
14. Chan A, Duker JS, Ko TH, Fujimoto JG, Schuman JS. Normal macular thickness measurements in healthy eyes using Stratus optical coherence tomography. Arch Ophthalmol. 2006;124(2):193-198. doi:10.1001/archopht.124.2.193

15. Acan D, Calan M, Er D, et al. The prevalence and systemic risk factors of diabetic macular edema: a cross-sectional study from Turkey. BMC Ophthalmol. 2018;18(1):91. doi:10.1186/s12886-018-0753-y

16. Browning DJ, Glassman AR, Aiello LP, et al. Optical coherence tomography measurements and analysis methods in optical coherence tomography studies of diabetic macular edema. Ophthalmology. 2008;115 (8):1366-1371, 1371.e1361. doi:10.1016/j.ophtha.2007.12.004

17. Liu MM, Wolfson Y, Bressler SB, Do DV, Ying HS, Bressler NM. Comparison of time- and spectral-domain optical coherence tomography in management of diabetic macular edema. Invest Ophthalmol Vis Sci. 2014;55(3):1370-1377. doi:10.1167/iovs.13-13049

18. Forooghian F, Cukras C, Meyerle CB, Chew EY, Wong WT. Evaluation of time domain and spectral domain optical coherence tomography in the measurement of diabetic macular edema. Invest Ophthalmol Vis Sci. 2008;49(10):4290-4296. doi:10.1167/iovs.08-2113

19. Baskin DE. Optical coherence tomography in diabetic macular edema. Curr Opin Ophthalmol. 2010;21(3):172-177. doi:10.1097/ ICU.0b013e32833866ae

20. Hwang TS, Jia Y, Gao SS, et al. Optical coherence tomography angiography features of diabetic retinopathy. Retina. 2015;35 (11):2371-2376. doi:10.1097/IAE.0000000000000716

21. Patel N, Chowdhury H, Leung R, Sivaprasad S. Sensitivity and specificity of time-domain versus spectral-domain optical coherence tomography in diabetic macular edema. Indian $J$ Ophthalmol. 2013;61(5):208-212. doi:10.4103/0301-4738.99848

22. Virgili G, Menchini F, Murro V, Peluso E, Rosa F, Casazza G. Optical coherence tomography (OCT) for detection of macular oedema in patients with diabetic retinopathy. Cochrane Database Syst Rev. 2011;7:Cd008081.

23. Al-Zamil WM, Al-Zwaidi FM, Yassin SA. Macular thickness in healthy Saudi adults. A spectral-domain optical coherence tomography study. Saudi Med J. 2017;38(1):63-69. doi:10.15537/smj.2017.1.17565

24. Mookiah MR, Acharya UR, Fujita H, et al. Application of different imaging modalities for diagnosis of diabetic macular edema: a review. Comput Biol Med. 2015;66:295-315. doi:10.1016/j. compbiomed.2015.09.012

25. Otani T, Kishi S, Maruyama Y. Patterns of diabetic macular edema with optical coherence tomography. Am J Ophthalmol. 1999;127(6):688-693.

26. Maalej A, Cheima W, Asma K, Riadh R, Salem G. Optical coherence tomography for diabetic macular edema: early diagnosis, classification and quantitative assessment. $J$ Clinic Experiment Ophthalmol. 2012;2012:S: 2.

27. Musat O, Cernat C, Labib M, et al. Diabetic macular edema. Rom J Ophthalmol. 2015;59(3):133-136.

28. Mastropasqua R, Di Antonio L, Di Staso S, et al. Optical coherence tomography angiography in retinal vascular diseases and choroidal neovascularization. $J$ Ophthalmol. 2015;2015:343515. doi:10.1155/ 2015/343515

29. Spaide RF, Fujimoto JG, Waheed NK. Optical coherence tomography angiography. Retina. 2015;35(11):2161-2162. doi:10.1097/IAE.0000000000000881

Clinical Ophthalmology

\section{Publish your work in this journal}

Clinical Ophthalmology is an international, peer-reviewed journal covering all subspecialties within ophthalmology. Key topics include: Optometry; Visual science; Pharmacology and drug therapy in eye diseases; Basic Sciences; Primary and Secondary eye care; Patient Safety and Quality of Care Improvements. This journal is indexed on PubMed
30. Toto L, D'Aloisio R, Di Nicola M, et al. Qualitative and quantitative assessment of vascular changes in diabetic macular edema after dexamethasone implant using optical coherence tomography angiography. Int $J$ Mol Sci. 2017;18(6):1181. doi:10.3390/ ijms 18061181

31. Samara WA, Shahlaee A, Adam MK, et al. Quantification of diabetic macular ischemia using optical coherence tomography angiography and its relationship with visual acuity. Ophthalmology. 2017;124 (2):235-244. doi:10.1016/j.ophtha.2016.10.008

32. Yamamoto S, Yamamoto T, Hayashi M, Takeuchi S. Morphological and functional analyses of diabetic macular edema by optical coherence tomography and multifocal electroretinograms. Graefes Arch Clin Exp Ophthalmol. 2001;239(2):96-101.

33. Wang N, Xu X, Zou H, Zhu J, Wang W, Ho PC. The status of diabetic retinopathy and diabetic macular edema in patients with type 2 diabetes: a survey from Beixinjing district of Shanghai city in China. Ophthalmologica. 2008;222(1):32-36. doi:10.1159/000109276

34. Heng LZ, Pefkianaki M, Hykin P, Patel PJ. Interobserver agreement in detecting spectral-domain optical coherence tomography features of diabetic macular edema. PLoS One. 2015;10(5):e0126557. doi:10.1371/journal.pone. 0126557

35. Hernandez-Martinez C, Palazon-Bru A, Azrak C, et al. Detection of diabetic macular oedema: validation of optical coherence tomography using both foveal thickness and intraretinal fluid. PeerJ. 2015;3: e1394. doi:10.7717/peerj.1394

36. Yang XL, Zou HD, Xu X. [Correlation of retinal sensitivity, visual acuity and central macular thickness in different types of diabetic macular edema]. [Zhonghua Yan Ke Za Zhi] Chin J Ophthalmol. 2013;49(12):1081-1088.

37. Wang YT, Tadarati M, Wolfson Y, Bressler SB, Bressler NM. Comparison of prevalence of diabetic macular edema based on monocular fundus photography vs optical coherence tomography. JAMA Ophthalmol. 2016;134(2):222-228. doi:10.1001/jamaophthalmol.2015.5332

38. Sikorski BL, Malukiewicz G, Stafiej J, Lesiewska-Junk H, Raczynska D. The diagnostic function of OCT in diabetic maculopathy. Mediators Inflamm. 2013;2013:434560. doi:10.1155/ 2013/434560

39. Bolz M, Schmidt-Erfurth U, Deak G, Mylonas G, Kriechbaum K, Scholda C. Optical coherence tomographic hyperreflective foci: a morphologic sign of lipid extravasation in diabetic macular edema. Ophthalmology. 2009;116(5):914-920. doi:10.1016/j. ophtha.2008.12.039

40. Browning DJ, McOwen MD, Bowen RM Jr, O’Marah TL. Comparison of the clinical diagnosis of diabetic macular edema with diagnosis by optical coherence tomography. Ophthalmology. 2004;111(4):712-715. doi:10.1016/j.ophtha.2003.06.028

41. Browning DJ, Fraser CM, Clark S. The relationship of macular thickness to clinically graded diabetic retinopathy severity in eyes without clinically detected diabetic macular edema. Ophthalmology. 2008;115(3):533-539.e532. doi:10.1016/j.ophtha.2007.06.042

42. Asensio-Sanchez VM, Gomez-Ramirez V, Morales-Gomez I, Rodriguez-Vaca I. [Clinically significant diabetic macular edema: systemic risk factors]. Arch Soc Esp Oftalmol. 2008;83 (3):173-176.
Central and CAS, and is the official journal of The Society of Clinical Ophthalmology (SCO). The manuscript management system is completely online and includes a very quick and fair peer-review system, which is all easy to use. Visit http://www.dovepress.com/ testimonials.php to read real quotes from published authors. 